\title{
Static and Cyclic Strength of Structural Carbon and Modified Steels
}

\author{
Mindaugas Kazimieras LEONAVIČIUS, Gediminas PETRAITIS, Eugeniuš STUPAK, \\ Stanislav STUPAK, Jelena SELIVONEC \\ Vilnius Gediminas Technical University, Saulètekioal.11,10223 Vilnius, Lithuania, E-mail: gediminas.petraitis@vgtu.lt \\ cross $^{\text {ref }}$ http://dx.doi.org/10.5755/j01.mech.23.6.17629
}

\section{Introduction}

The individual components of mineral mills and crushers are made of various grades steel and cast iron. In work [1] descriptions and specifications of various crushers' structures are observed. The main schemes of crushers' structures are shown in Fig. 1. The worst loaded upper and lower conic elements during operation are exposed to static, cyclic and dynamic loads. The operational failures as usually occur due to various causes and show complicated fracture character. Is it determined by structures elements' configuration or either is consequence of failure process in micro and macro volumes, is dependent on alternating load and on other factors. Material 's suitability for mills ' production should be evaluated in various views. The main elements serve multifunctional purpose when load conditions are very complicated. Not always it is possible to evaluate overall load spectre by experiments. Therefore, there are distinguished the most important mechanical properties i.e. static mechanical properties, resistance for cyclic and dynamic loading, and wear. Many works are dedicated [2-14] for solving of these problems. In this work suitability of carbon steel for manufacturing of crushers' elements was studied. Even slight changes of chemical composition and heat treatment would result the different resistance for static and cyclic loading.

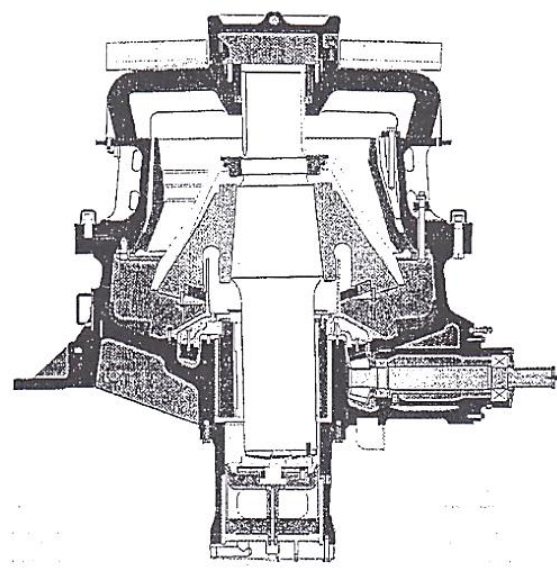

b

Fig. 1 Schemes of conic crushers 'structures: $a$ - mechanical adjustment; $b$ - hydro mechanical adjustment

\section{Experiment}

Two sorts of carbon steel were used for experimental study, which further in the text will be relatively identified as CS500 and CS700. Chemical composition of steel CS500: C - 0.25, $\mathrm{Mn}-1.2, \mathrm{P}-0.05, \mathrm{~S}-0.035, \mathrm{Si}-$ $0.8, \mathrm{Ni}-0.3, \mathrm{Cu}-0.3$. Steel's CS700: $\mathrm{C}-0.35, \mathrm{Mn}-1.75$ $\mathrm{Si}-1, \mathrm{~S}-0.04, \mathrm{P}-0.04, \mathrm{Ni}-0.5, \mathrm{Cr}-0.25, \mathrm{Mo}-0.2, \mathrm{Cu}$ -0.3 .

Different heat treatment was applied for both studied steels: CS500 was normalized, CS700 - quenched and tampered. During quenching the higher hardness and strength is received. Faster cooling and lower tempering temperatures results the higher hardness. Normalization (obtained structure pearlite + ferrite) thought gives similar impact toughness indices as the tempering, but increases the resistance to crack propagation.

Microstructure of steel CS500 is presented in Fig. $2 \mathrm{a}$ and consists of ferrite and pearlite. Pearlite is of plates and grains form. Lighter zones of microstructure are ferrite; which grains' boundaries are visible quite clear. There is observable uneven distribution of ferrite and pearlite.

Microstructure of steel CS700 is presented in Fig. 2. Structure is more even, consists of ferrite and pearlite, therefore it is possible to observe several microstructural inhomogeneities. In places it is finer, in the others coarser. The finer microstructure influences the hardness and static mechanical properties. Decreasing in grain size and decreasing amount of pearlite, strength and ductility increase. For other specimens the spots were detected. These are the inhomogeneities' inserts such as oxides and sulphides. These inserts also influence the toughness. They may cause the brittle fracture. Pearlite forms after eutectoid point when single phase austenite splits into two phases, cementite and ferrite.

For mechanical properties determination there were manufactured round tensile (diameter $10 \mathrm{~mm}$, gauge 
length $50 \mathrm{~mm}$ ) specimens. Tensile tests were carried out and the main indicators of the mechanical properties were calculated in accordance with the standard ISO 68921:2009. Modulus of elasticity was determined according to the standard ASTM E111-88. The obtained main static

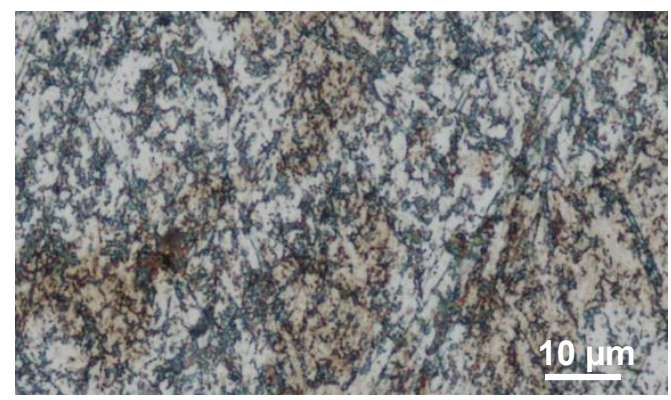

a mechanical properties in within the group are very similar: steel's CS500 yield point $R_{\mathrm{el}}=300 \mathrm{MPa}$; tensile stress $R_{\mathrm{m}}=512 \mathrm{MPa}$; elasticity modulus $E=200 \mathrm{GPa}$. Respectively for steel CS700: $R_{0.2}=506 \mathrm{MPa}$ (offset yield stress); $R_{\mathrm{m}}=702 \mathrm{MPa} ; E=207 \mathrm{GPa}$.

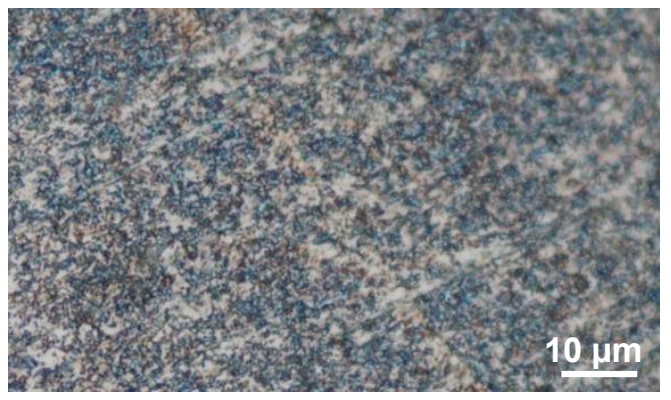

b

Fig. 2 Microstructure: a - steel CS500; b - steel CS700

Tensile test diagrams of all the specimens of steel CS500 within the group exposed the yield point. Steel's CS700 tensile diagrams hadn't exhibited the yield point. For all tensile diagrams of steel CS500 there are visible vivid initial sticking teeth of upper yield point. Steel's CS700 reduction of area after break $Z=50 \ldots 55 \%$, for steel CS500 - Z = 65 ... $66 \%$. Steel's CS700 relative elongation after break $A$ was $17.7 \ldots 19.5 \%$, steel's CS500 relative elongation $A$ was $26.6 \ldots 28 \%$. Hence steel CS700 is noticeably less ductile in comparison with steel CS500.

The hardness was determined for work-pieces, from which the CT specimens were manufactured: steel CS500 - 164 BHN, steel CS700 - 244 BHN.

For experimental testing of resistance to cyclic loading and dependencies of stress intensity factor range $\Delta K$ vs. crack propagation rate $d a / d N$ drawing there were manufactured by four CT specimens of each steel, CS500 and CS700. Compact tensile (CT) specimens' dimensions are shown in Fig. 3.

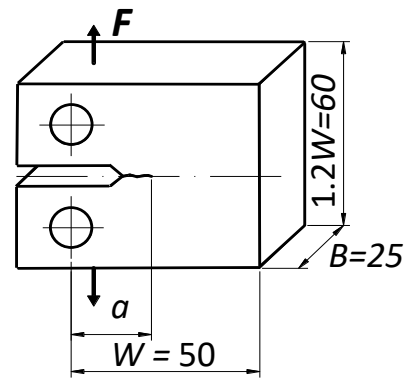

Fig. 3 CT specimen

The experiments and results analysis were carried out by the standard ASTM 647-00. Methodizes were extended, i.e. $\Delta K_{\text {th }}$ was recorded at rate close to $d a / d N \approx 1 \cdot 10^{-11} \mathrm{~m} /$ cycle. For further analysis, it was taken by two CT specimens of each group. Test results are shown in Fig. 4.

The nominal stresses and the stress intensity factors were calculated by the ASTM E 647-00 formula:

$$
\begin{aligned}
& \sigma=\frac{2 F}{B W} \cdot \frac{2+\lambda}{(1-\lambda)^{2}}, \\
& K=\left(F / W^{1 / 2}\right) \cdot f(\lambda),
\end{aligned}
$$

where: $f(\lambda)=\left[\frac{(2+\lambda)}{(1-\lambda)^{3 / 2}}\right] \cdot\left(\begin{array}{l}0.866+4.64 \lambda-13.32 \lambda^{2} \\ +14.72 \lambda^{3}-5.6 \lambda^{4}\end{array}\right)$,

$\lambda=a / W, F$ is tensile force, $B$ is specimen's thickness, $W$ is specimen's basis, $a$ is crack size.

Stress intensity factor range:

$$
\Delta K=K_{\max }-K_{\min }
$$

According to the standard, crack's propagation front is limited by some kind of requirements. For large scale structural elements due to complicity of manufacturing process, heterogeneities and various derivatives are formed, which may cause the problems during operation. These derivatives and defects are difficult to detect by nondestructive control methods. To evaluate operational fractures, sometimes it is needed to produce CT specimens of fractured element. Performing the experiments, the resulting crack front may gain complicated configuration. Crack's observing during tests is complicated. By optical means fixed crack size on sides of CT specimen noticeably differs and doesn't reveals the true crack front. Only after specimens' collapse, from fracture it is possible to specify crack front and to apply the derived data for calculations. Steel's CS500 threshold stress intensity factor (Fig. 4, b) was for specimen CT3 $-\Delta K_{t h} \approx 17.5 \mathrm{MPa} \cdot \sqrt{\mathrm{m}}$, for CT4 $\Delta K_{\text {th }} \approx 18 \mathrm{MPa} \cdot \sqrt{\mathrm{m}}$.

In Figs. 5 and 6 there are presented the specimens' CT1 and CT2 fractures and SEM images of separate locations. Specimen CT1 had been broken statically when crack depth reached $\approx 25 \mathrm{~mm}$. Specimen CT2 broken during cyclic loading. Fatigue zones of fractures are similar and corresponds to the known high cycle failure laws. They slightly differ in number of crack initiation tongues and by manner of coupling into the common crack front. There are visible retardation traces formed during cyclic loading. Also insignificant tunneling effect took place. On specimens' fractures there are visible the effects of microstructure. They are of steel CS700 which structural components are ferrite and pearlite (in plates and grains) and are noticeable in fractures. We can also clearly see uneven ferrite and pearlite distribution in separate SEM images.

In Figs. 5, a, b, c, d and e presented the speci- 
men's CT1 images of separate zones confirmed visually uniform fracture's structure. In all zones we see nonmetalic inserts, which haven't done the noticeable impact and haven't distorted the crack front. Just in localized environment, complicated failure process took place, with sets of facets, isolated by separate dimples. There are noticeable fissures, formed during failure process.

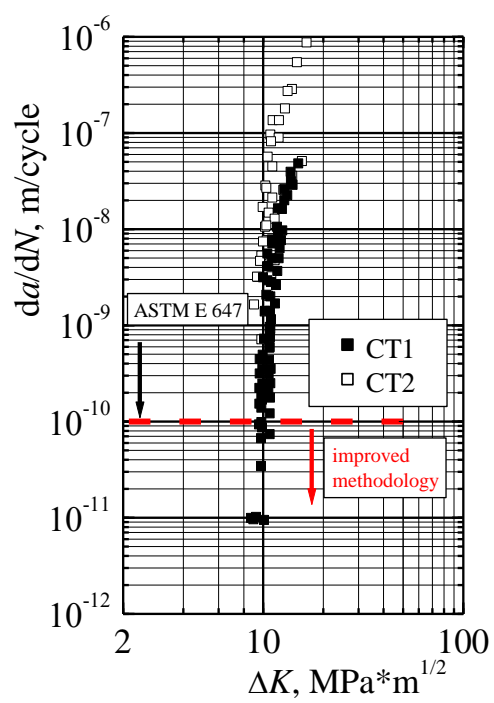

a

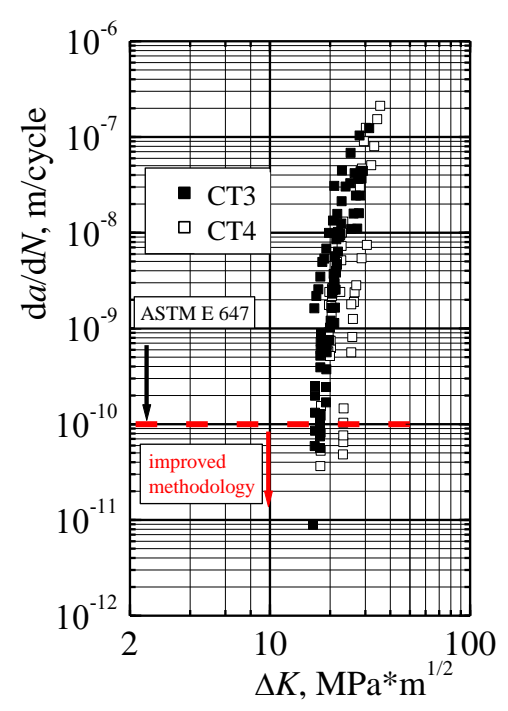

b

Fig. 4 Dependence of stress intensity factor range $\Delta K$ and crack propagation rate $d a / d N$ : a - steel CS700; b steel CS500

On CT2 fracture surface, shown in (Fig. 6, $a$ ) we see small rises and indentations. Common failure process is characterized by in (Fig. 6, $b$ ) and c presented images. We see split crystals, cleavage facets, cavities of various shape and size. Large and deep extortions in material show complicated failure process. Residual fractures on fractured surface are the secondary cracks. In aside presented images $d$ and e there are highlighted several zones. We see microvoids, flokens and various derivatives. These derivatives haven't influence the common crack front, however in their surroundings failure process changes. In localized environment, failure mechanism has brittle and ductile fracturing signs. Local crack propagation direction de- pended on grain crystallographic planes' orientation and differed in micro level and general crack propagation direction. Transgranular failure mechanism have changed into the intergranular and there are visible ductile failure traces' dimples.

In specimens' CT3 and CT4 fractures, shown in Figs. 7 and 8 there are illustrated the challenges to evaluate materials' suitability for structural elements manufacturing. Deciding according to the fracture structure, specimen CT3 was divided (Fig. 7a) into two parts (approximately in the middle) due to inhomogeneity of material. The initial crack zone show that crack in the right hand side and in the left hand side initiated in different ways. To the left, there were many crack's initiations, which merged into one front at the depth of $\approx 2 \ldots 3 \mathrm{~mm}$. In the middle, crack initiated in opposite plane of the notch. Under inhomogeneous derivatives' influence, separate tongues spread and merged with the common crack at the depth of $\approx 15 \mathrm{~mm}$. Crack's skew in the left and in the right is the consequence of material's unevenness. In specimen's CT3 zone "b" we see inserts of inhomogeneities, such as nitrides, oxides, carbides and sulphides. If these derivatives are located in specimen's notch vicinity, they influence the crack initiation and tongues' formation. During deformation process the flockens had distinguished - round or ellipsoid internal fractures, like to flakes of silver tone. They change the direction of fatigue traces and influence the crack propagation. In this zone we can also see dimples, which were formed due to mixed intergranular ductile fracturing. In (Fig. 7,c) there is shown an interesting formation, formed during material's manufacturing process and emerged on the fractured surface. It can be assign to microliquation process. It's the dendrite, of pyramid form and formed in vicinity of cavity. In the cavity's surroundings complicated failure process took place, with various directions of fatigue traces, river relief with the signs of brittle and ductile failure signs.

In (Fig's. 8, $a$ ) left hand side there is seen the structural inhomogeneity, having complicated contour (area $\approx 5 \mathrm{~mm}^{2}$ ) and formed during material's manufacturing process. In (Fig. 8, $b$ ) there is separated part of fracture, enlarged 5 times, in which failure process, deciding from fracture, differs from common failure mechanism. From depth $\approx 12 \mathrm{~mm}$ the retardations of partial crack front began. In fracture's left and right we see some differences. In the left crack was retarded, then it accelerated and passed this zone and aligned again with right side's crack. From this zone, were taken two images " $d$ " and "e" in which fracture character is like to the zone's "f" fracture, i.e. intergranular cleavage. It should be noted, that zone "f" is in the specimen's CT4 static fracture zone.

Structural inequality affected failure process in the manner that in separate zones different failure mechanisms occurred. Stress state (CT4) adjust crack propagation front. For crack depth up to $8 \mathrm{~mm}$, the crack front corresponded the regular lows of crack propagation. Increasing depth there is noticeable significant tunneling effect. Occurred small localized inhomogeneties (zone f) haven't made the significant influence on common front. During static break up on the specimen's sides ductile fracture occurred.

In the static failure zone on specimens' CT3 and CT4 sides ductile fracture took place. Tunneling effect in the fatigue and static fracture zones is consequence of 
stress state which formed the signs of ductile failure. Fracture's structure, shown in (Fig. 8) and near tunnel's peak, is practically the same. Fracture surface has texture of grains and facets, fatigue traces are turned in various directions. A like fracture structure had specimen CT3. Sectioning is a mixture of fractured plate pearlite.

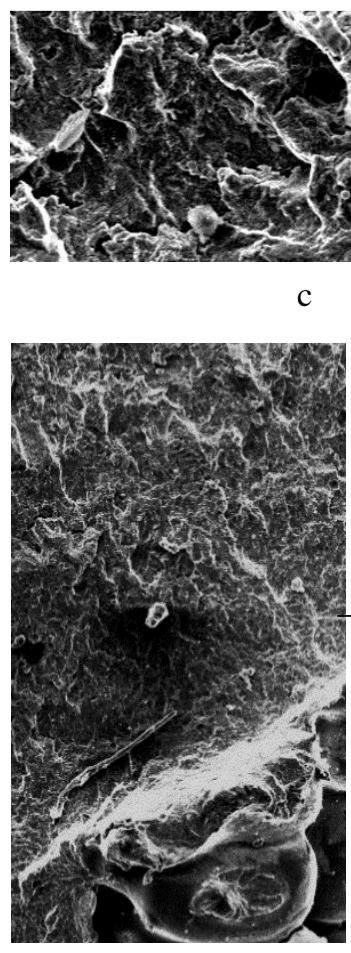

$\mathrm{b}$

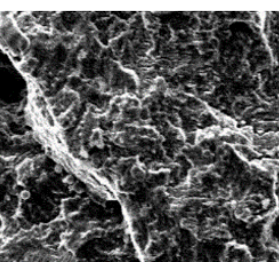

c

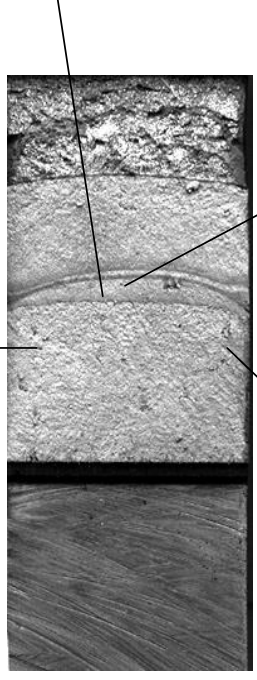

a

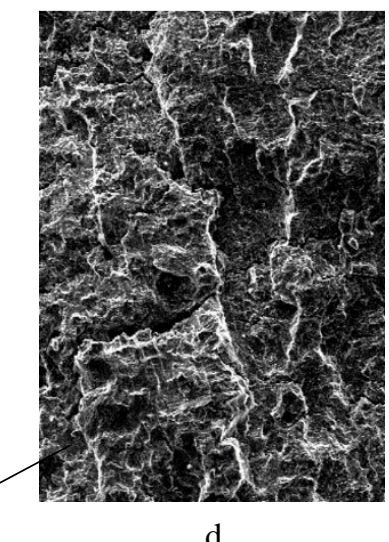

d

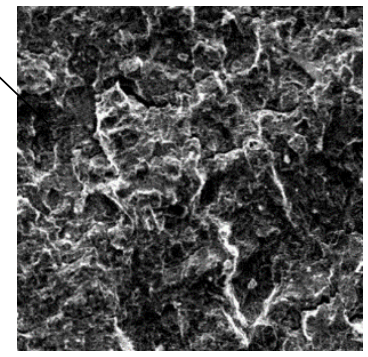

$\mathrm{e}$

Fig. 5 Fracture surface of specimen CT1: a - break: b (x160), c (x600), d (x160), e (x160) - SEM images of separate zones

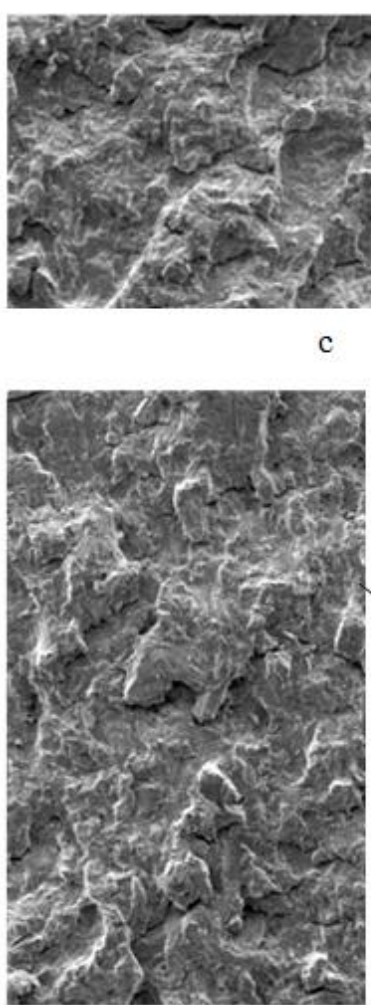

b
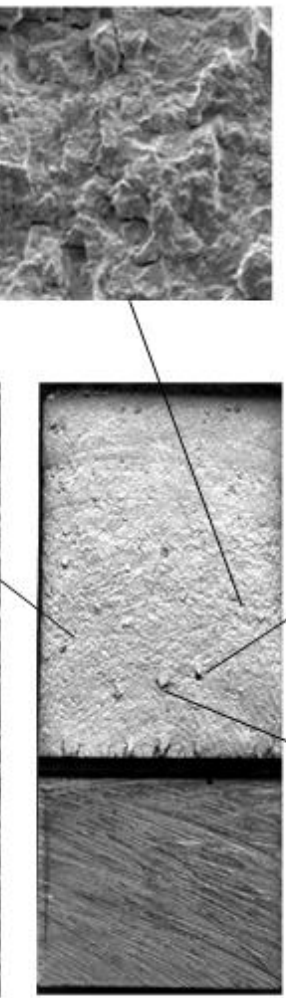

a

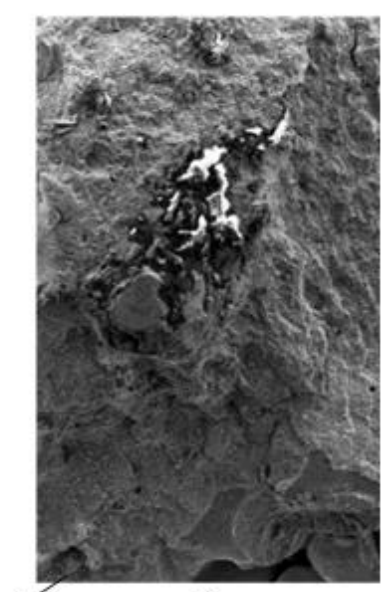

d

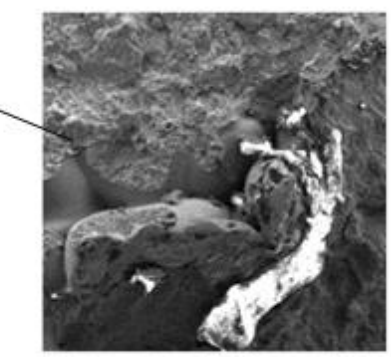

e

Fig. 6 Fracture surface of specimen CT2: a - break: b (x160), c (x160), d (x75), e (x75) - SEM images of separate zones 


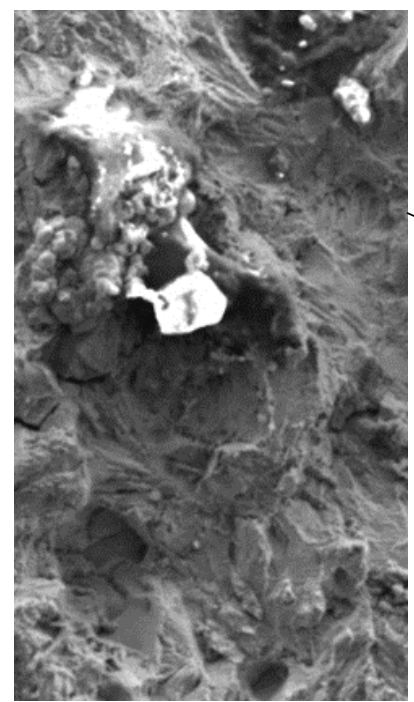

$\mathrm{b}$

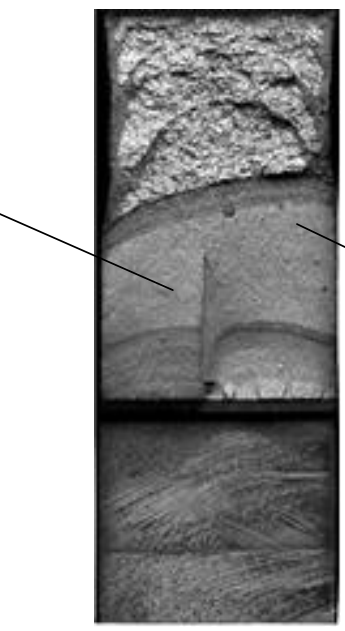

a

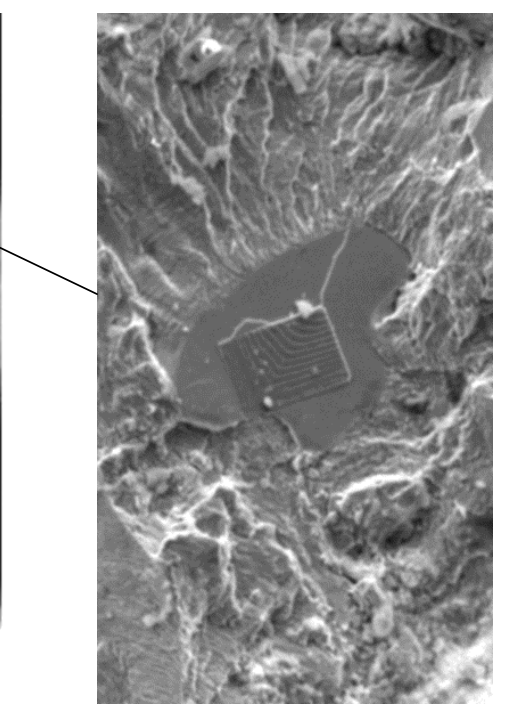

c

Fig. 7 Fracture surface of specimen CT3: a - break: b (x300), c (x600) - SEM images of separate zones
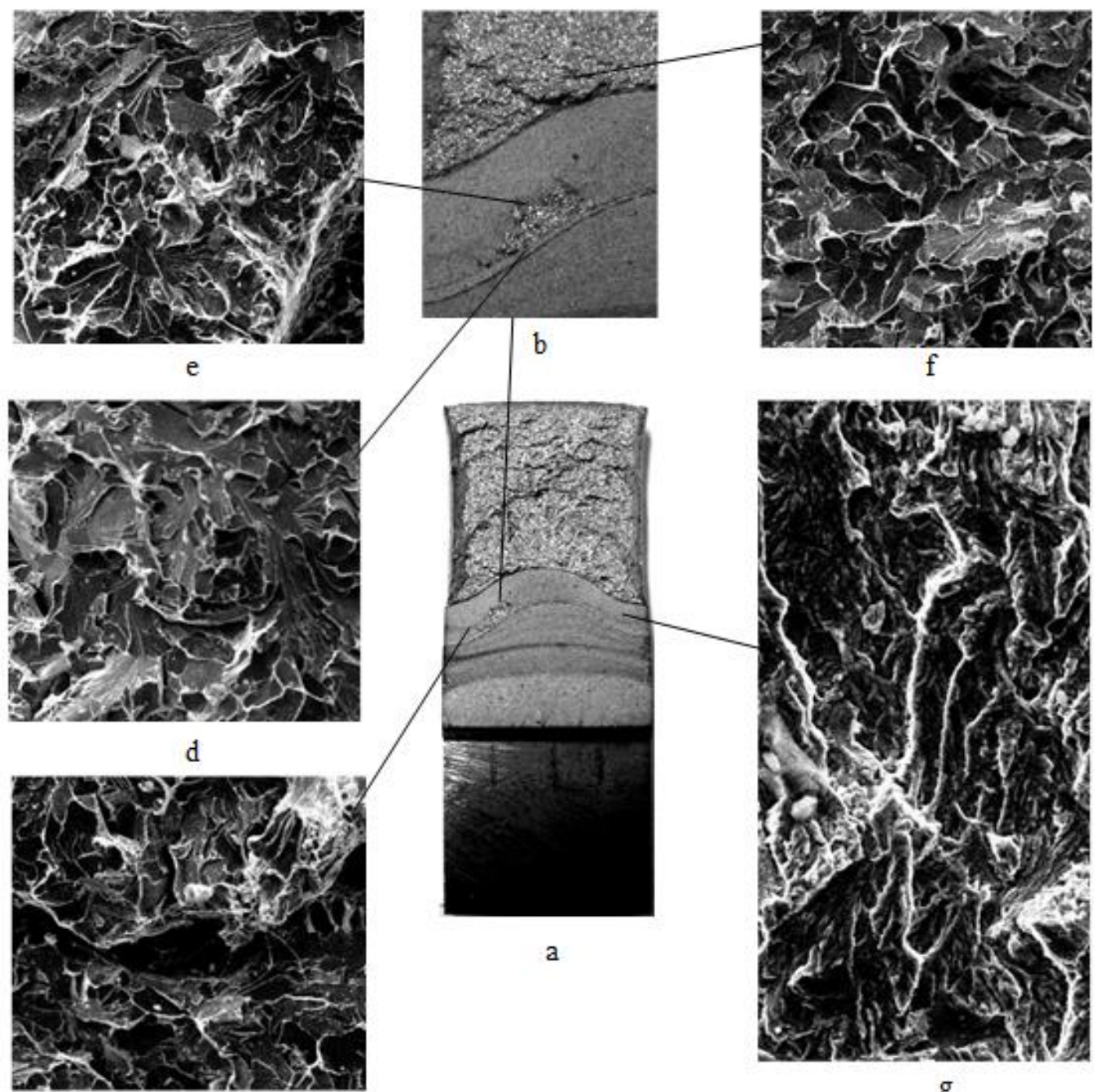

c

g

Fig. 8 Fracture surface of specimen CT4: a, b - break: c (x160), d (x160), e (x160), f (x160), g (x600) - SEM images of separate zones

Specimens' ${ }^{\circ}$ T3 and CT4, manufactured of plate steel, failure process under cyclic load takes longer, in comparison with specimens ${ }^{\circ} \mathrm{CT} 1$ and $\mathrm{CT} 2$ failure process.

\section{Conclusions}

1. Determined static mechanical properties: 
CS700 (quenched and tempered) $-R_{\mathrm{m}}=700 \mathrm{MPa}$, $A=18 \%, \quad \mathrm{Z}=50 \ldots 55 \% ; \quad \mathrm{CS} 500 \quad$ (normalized) $R_{\mathrm{m}}=500 \mathrm{MPa}, A=27 \%, Z=65 \%$. Steel CS500 had clearly expressed yield point $R_{\mathrm{el}}=300 \mathrm{MPa}$, for steel CS700 the offset yield point was determined $R_{0.2}=500 \mathrm{MPa}$. Steel CS500 is noticeably more plastic.

2. Threshold stress intensity factor of steel CS700 was for specimen $\mathrm{CT} 1-\Delta K_{\mathrm{th}} \approx 10 \mathrm{MPa} \cdot \sqrt{\mathrm{m}}$, while for specimen CT2 - $\Delta K_{\text {th }} \approx 9 \mathrm{MPa} \cdot \sqrt{ } \mathrm{m}$. Performed fracture analysis with SEM showed that the intergranular failure was prevailing, fatigue surface was lighter in colour.

3. Steel's CS500 threshold stress intensity factor was for specimen CT3 $-\Delta K_{\mathrm{th}} \approx 17.5 \mathrm{MPa} \cdot \sqrt{\mathrm{m}}_{\mathrm{m}}$, for CT4 $\Delta K_{\mathrm{th}} \approx 18 \mathrm{MPa} \cdot \sqrt{\mathrm{m}}$. Analysis performed with SEM showed that during failure process, brittle and ductile failure mechanisms took place at one time. In the fracture there is reflected fibrous structure, matted shade and grained glossy zones.

4. Insignificant inserts, micro-cavitations and obscure structure's derivatives haven't show the special effect on failure process, their influence was experienced just in localized zones. Discrepancies of crack front show, that crack pass inhomogeneous microstructures zones.

\section{References}

1. Moore, P. 2008. Conical crushing. Mining magazine 5: 35-42.

2. Wei, D.Y.; Gu, J.L.; Fang, H.S.; Bai, B.Z.; Yang, Z.G. 2004. Fatigue behavior of $1500 \mathrm{MPa}$ bainite/martensite duplex-phase high strength steel. Int. J Fatigue 26: 437-442. http://dx.doi.org/10.1016/j.ijfatigue.2003.06.003.

3. Beck, T.; Kovacs, S. L. 2013. Singheister. Influence of high mean stresses on lifetime and damage of the martensitic steel X10CrNiMoV12-2-2 in the VHCFregime. 13th Int. Conf on Fracture, Beijing, China. 210.

4. Li, S.X. 2012. Effects of inclusions on very high cycle fatigue properties of high strength steels. Int. Mater. Rev. 57: 92-114. http://dx.doi.org/10.1179/1743280411Y.0000000008.

5. Sakai, T. 2009. Review and Prospects for Current Studies on Very High Cycle Fatigue of Metallic Materials for Machine Structural Use. International Journal of Fatigue 3: 425-439.

http://dx.doi.org/10.1299/jmmp.3.425.

6. Mughrabi, H. 2006. Specific features and mechanisms of fatigue in the ultrahigh-cycle regime. International Journal of Fatigue 28: 1501-1508. http://dx.doi.org/10.1016/j.ijfatigue.2005.05.018.

7. Wang, Q.Y.; Bathias, C.; Kawagoishi, N.; Chen,Q. 2002. Effect of inclusion on subsurface crack initiation and gigacycle fatigue strength. International Journal of Fatigue 24: 1269-1274. http://dx.doi.org/10.1016/S0142-1123(02)00037-3.

8. Murakami, Y.; Kodama, S.; Konuma, S. 1989. Quantitative evaluation of effects of non-metallic inclusions on fatigue strength of high strength steels. Int. J.
Fatigue 11: 291-298.

http://dx.doi.org/10.1016/0142-1123(89)90054-6.

9. Yang, Z.G.; Li, S.X.; Li, Y.D.; Liu, Y.B.; Hui, W.J.; Weng, Y.Q. 2010. Relationship among fatigue life, inclusion size and hydrogen concentration for highstrength steel in the VHCF regime. Materials Science and Engineering 527: 559-564.

http://dx.doi.org/10.1016/j.msea.2009.10.056.

10. Furuya, Y.; Matsuoka, S.; Abe, T.; Novel, A. 2003. Inclusion Inspection Method Employing $20 \mathrm{kHz} \mathrm{Fa-}$ tigue Testing. Metallurgical and Materials Transactions 34: 2517-2526.

http://dx.doi.org/10.1007/s11661-003-0011-6.

11. Murakami, Y.; Endo, M. 1994. Effects of defects, inclusions and inhomogeneities on fatigue strength. Int. J. Fatigue 16(3): 163-82. http://dx.doi.org/10.1016/0142-1123(94)90001-9.

12. Mughrabi, H. 2002. On 'multi-stage' fatigue life diagrams and the relevant life-controlling mechanisms in ultrahigh-cycle fatigue. Fatigue and Fracture of Engineering Material and Structures 25(8): 755-64. http://dx.doi.org/10.1046/j.1460-2695.2002.00550.x.

13.Sakai, T,; Sato, Y.; Oguma, N. 2002. Characteristic $\mathrm{S}-\mathrm{N}$ properties of high-carbon-chromium bearing steel under loading in long-life fatigue. Fatigue and Fracture of Engineering Material and Structures 25(8-9): 765773.

http://dx.doi.org/10.1046/j.1460-2695.2002.00574.x.

14. Krasauskas, P.; Kilikevičius, S.; Česnavičius, R.; Pačenga, D. 2014. Experimental analysis and numerical simulation of the stainless AISI 304 steel friction drilling process. Mechanika 20(6): 590-595. http://dx.doi.org/10.5755/j01.mech.20.6.8664.

M. K. Leonavičius, G. Petraitis, E. Stupak, S. Stupak, J. Selivonec

\section{STATIC AND CYCLIC STRENGTH OF STRUCTURAL CARBON AND MODIFIED STEELS}

S u m m a r y

In the article there are presented the results of experimental analytical study of the similar chemical composition but differently heat-treated structural steel: mechanical properties and resistance to cyclic loading. The indicators of strength, plasticity and cyclic failure process were determined. Fracture analysis of compact specimens (CT) was performed with SEM. It was attempted to validate the relation of mechanical properties $\left(R_{m}=500 \mathrm{MPa}\right.$ for CS500 steel and $R_{m}=700 \mathrm{MPa}$ for CS700 steel) with stress intensity factor $\left(\Delta K_{t h}=18 \mathrm{MPa} \cdot \sqrt{\mathrm{m}}\right.$ for CS500 steel and $\Delta K_{t h}=10 \mathrm{MPa} \cdot \sqrt{\mathrm{m}}$ for CS700 steel).

Keywords: steel, fatigue, fracture, threshold.

Received April 27, 2017

Accepted December 07, 2017 